BMJ Open

Diabetes

Research

\& Care

\title{
Cost-effectiveness analysis of a pharmacotherapeutic empowerment strategy for patients with type 2 diabetes mellitus
}

\author{
Ana Carolina Oliveira Gonçalves, ${ }^{1}$ Maurílio de Souza Cazarim, ${ }^{2}$ \\ Cristina Sanches, ${ }^{3}$ Leonardo Regis Leira Pereira, ${ }^{2}$ Ana Márcia Tomé Camargos, ${ }^{3}$ \\ Jéssica Azevedo Aquino, ${ }^{3}$ Andre Oliveira Baldoni ${ }^{3}$
}

To cite: Gonçalves ACO, Cazarim MdS, Sanches C, et al. Cost-effectiveness analysis of a pharmacotherapeutic empowerment strategy for patients with type 2 diabetes mellitus. BMJ Open Diab Res Care 2019;7:e000647. doi:10.1136/ bmjdrc-2018-000647

Received 11 January 2019 Revised 13 May 2019 Accepted 3 June 2019
Check for updates

C) Author(s) (or their employer(s)) 2019. Re-use permitted under CC BY-NC. No commercial re-use. See rights and permissions. Published by BMJ.

${ }^{1}$ Universidade Federal de São João del-Rei - Campus CCO,

Sao Joao del-Rei, Brazil

${ }^{2}$ Faculty of Pharmaceutical

Sciences of Ribeirão Preto,

University of São Paulo,

Ribeirão Preto, São Paulo, Brazil

${ }^{3}$ Faculdade de Farmácia,

Universidade Federal de Sao

Joao del-Rei - Campus CCO,

Sao Joao del-Rei, Brazil

Correspondence to Dr Ana Carolina Oliveira

Gonçalves;

aco_goncalves@yahoo.com.br

\section{ABSTRACT}

Background The economic feasibility of pharmacotherapeutic empowerment of patients with type 2 diabetes mellitus (DM2) is still not well established. Objectives To evaluate the cost-effectiveness of an individual pharmacotherapeutic empowerment strategy (IPES) for patients with DM2.

Methods This is a cost-effectiveness study nested in a non-randomized clinical trial with patients $\geq 18$ years of age, of both genders, with low and moderate cardiovascular risks. This study was carried out from the perspective of the municipal health system of Divinópolis in Minas Gerais state, and compared patients submitted to an IPES and patients who received only traditional care, 1 year before the beginning of the intervention (baseline) and 1 year after its completion (follow-up). The costs of the services offered by the municipality were computed, and in the intervention group IPES costs were included. Glycated hemoglobin (A1C) was the effectiveness parameter adopted. Cost-effectiveness ratio analyses, incremental cost-effectiveness ratio (ICER), and sensitivity analysis were performed.

Results In the analysis of cost-effectiveness, it is observed that a reduction of 0.359 in A1c costs US $\$ 708.47$ in the intervention group and a reduction of 0.170 costs US $\$ 1927.13$ in the control group. Thus, the ICER is US $\$ 387.66$ per patient/year. In the sensitivity analysis, it was observed that the IPES was dominant in $19.8 \%$ of the simulated scenarios and cost-effective in $80.2 \%$.

Conclusions The IPES is an alternative that presents economic feasibility for the municipal public health system scenario. The absence of randomization in patient selection is a limitation of this study.

\section{INTRODUCTION}

Diabetes mellitus (DM) type 2 (DM2) is characterized by hyperglycemia and is the most prevalent $(90 \%)$ and usually affects overweight individuals over 40 years of age. ${ }^{12}$

DM2 is a chronic, slowly evolving disease and can lead to micro/macrovascular complications in patients, ${ }^{13}$ which depending on severity leads to significant worsening of patients' quality of life. ${ }^{45}$ The contemporary

\section{Significance of this study}

What is already known about this subject?

- It is known that pharmacotherapeutic empowerment is a clinically effective alternative in the control of type 2 diabetes mellitus.

What are the new findings?

- Pharmacotherapeutic empowerment is confirmed as a clinically effective alternative and, in addition, as an economically viable strategy from the perspective of the municipal public health system.

How might these results change the focus of research or clinical practice?

- The results can contribute to the generation of data of pharmacoeconomic research developed at a municipal level of the management of the public health system. It can also encourage municipal managers to implement similar strategies promoting improved glycemic control of patients and the application of financial resources.

scenario, with a high prevalence of DM2, contributes to the increase of direct and indirect costs, making financial equilibrium a growing challenge for health systems. ${ }^{67}$

It is estimated that in Brazil the annual expenditure with DM is around US\$3.9 billion and that the average cost of a patient with DM2 for the public health system (PHS) is US\$2108.00/year. ${ }^{8}$ The WHO estimates that the costs of loss of productivity of a patient with DM can exceed up to five times the direct costs of the disease. ${ }^{2}$

In this sense, alternatives that effectively help reduce the costs of treating patients with DM2 become relevant to health systems. ${ }^{9}$

Individual pharmacotherapeutic empowerment emerges as a tool to assist the individual in daily self-care, providing knowledge about pharmacological treatment and contributing 
to the promotion of glycemic control, ${ }^{10-13}$ however, there are still few studies that associate the use of this strategy with financial results.

This study aims to foster the production of economic data related to individual pharmacotherapeutic empowerment strategies (IPES) for patients with DM2 from the perspective of primary healthcare in the municipal public system.

\section{RESEARCH DESIGN AND METHODS}

The present study is a pharmacoeconomic study nested in a concurrent clinical trial with non-randomized control, and analyzed an IPES in patients with DM2, performed by Aquino et al, ${ }^{14}$ comparing it to traditional care offered to patients with DM2 in primary healthcare, from the perspective of the municipal public service.

The study included patients with DM2 registered in the system for enrollment and follow-up of patients with arterial hypertension and DM, attended by the PHS (Hiperdia), aged 18 years and over, of both genders, living in the territories served by the Family Health Strategy (FHS), with low and moderate cardiovascular risks, according to the Framingham score. ${ }^{15}$ In the intervention group, the participants attended all the IPES meetings. Patients in the control group did not participate in any IPES meeting. To detect a difference of 0.67 in mean glycated hemoglobin (A1c) ${ }^{16}$ a minimum population of 60 patients was required for the composition of the intervention group. To achieve this number, $100 \%$ of the patients who fulfilled the inclusion criteria were invited to participate in the study. With the exhaustion of the eligible population in the recruitment of the intervention group, the control group consisted of patients who refused to participate in the intervention and patients who were not located in their homes during recruitment.

To minimize the effects of lack of randomization on selection, patients in the control group were categorized into patients who declined to participate in the intervention, and patients who were not found during the recruitment process, and sociodemographic variables were compared between these two categories.

Participants of other intervention projects related to DM education, patients with reduced cognitive ability (classified by the FHS team as unable to reproduce the information received), and patients without A1c results registered in the computerized health system (Integrated Health System, IHS) in the reference period for data collection (criterion only for the control group) were excluded.

The IPES performed by Aquino et al (2018) consisted of three meetings between the pharmacist and the patient, with the aim of empowering the patient for self-care. As a tool for empowerment, a booklet was used with guidelines on DM2 and use of antidiabetic medication. If there was a limitation on the use of the booklet, it would be delivered to a family member or caregiver. ${ }^{14}$ Both groups continued to receive traditional care offered by primary healthcare, which consisted of consultations with general practitioners and specialists, nursing consultations, access to medication, urgent and emergency services, and hospital services (figure 1).

The health outcome used as an effective parameter was A1c, since it is the best parameter for monitoring and follow-up patients with DM2. ${ }^{3}$ Data were collected considering the period of 1 year before the beginning of the intervention (baseline) and 1 year after its closure (follow-up).

In order to calculate the costs involved in the care of these patients, the medications used, medical consultations in basic care, consultations with specialists in ophthalmology, cardiology, endocrinology, general surgery, angiology and nephrology, nursing consultations, urgent and emergency healthcare, hospitalization, and the cost of medication were considered. In the case of the intervention group, the cost of care with the IPES pharmacist was added. The number of procedures, collected 1 year before the beginning of the intervention (baseline) and 1 year after its closure (follow-up), through consultations with the IHS, the patient's records and the data collected during the IPES of each patient were multiplied by their respective cost that was established by different methods (figure 2).

Cost-effectiveness ratio analyses (equation 1) were performed to evaluate the results achieved with the IPES. For the calculation, the mean of the total annual cost of each of the groups in the follow-up period compared with the difference of A1c between follow-up and baseline was considered. The incremental cost-effectiveness ratio (ICER) was calculated based on equation $2 .^{18}$

$$
\text { CER intervention }=\frac{\text { total cost intervention }}{\text { effectiveness intervention }}
$$

and

$$
\begin{gathered}
\text { CER control }=\frac{\text { total cost control }}{\text { effectiveness control }} \\
\text { ICER }=\frac{(\text { total cost intervention }- \text { total cost control })}{(\text { effectiveness intervention }- \text { effectiveness control })}
\end{gathered}
$$

Sensitivity analysis was performed to determine how robust was the adopted modeling, reducing the degree of uncertainty of cost estimation and cost relation with the effects produced by the intervention. ${ }^{19}$ Scenarios for the comparison were constructed considering the variations in the total cost of the monitoring period (mean, minimum and maximum) of each of the groups and the same variations of A1c difference (table 1). The IPES was considered dominant when presenting lower cost and better outcome. For trade-off scenarios the calculated ICER and IPES were considered very cost-effective when the values were lower than the gross domestic product (GDP) per capita, which was US\$9966.21. ${ }^{20}$ ICER with values of up to three times the GDP per capita (US\$29 $898.63)^{20}$ characterizes the intervention as cost-effective. 


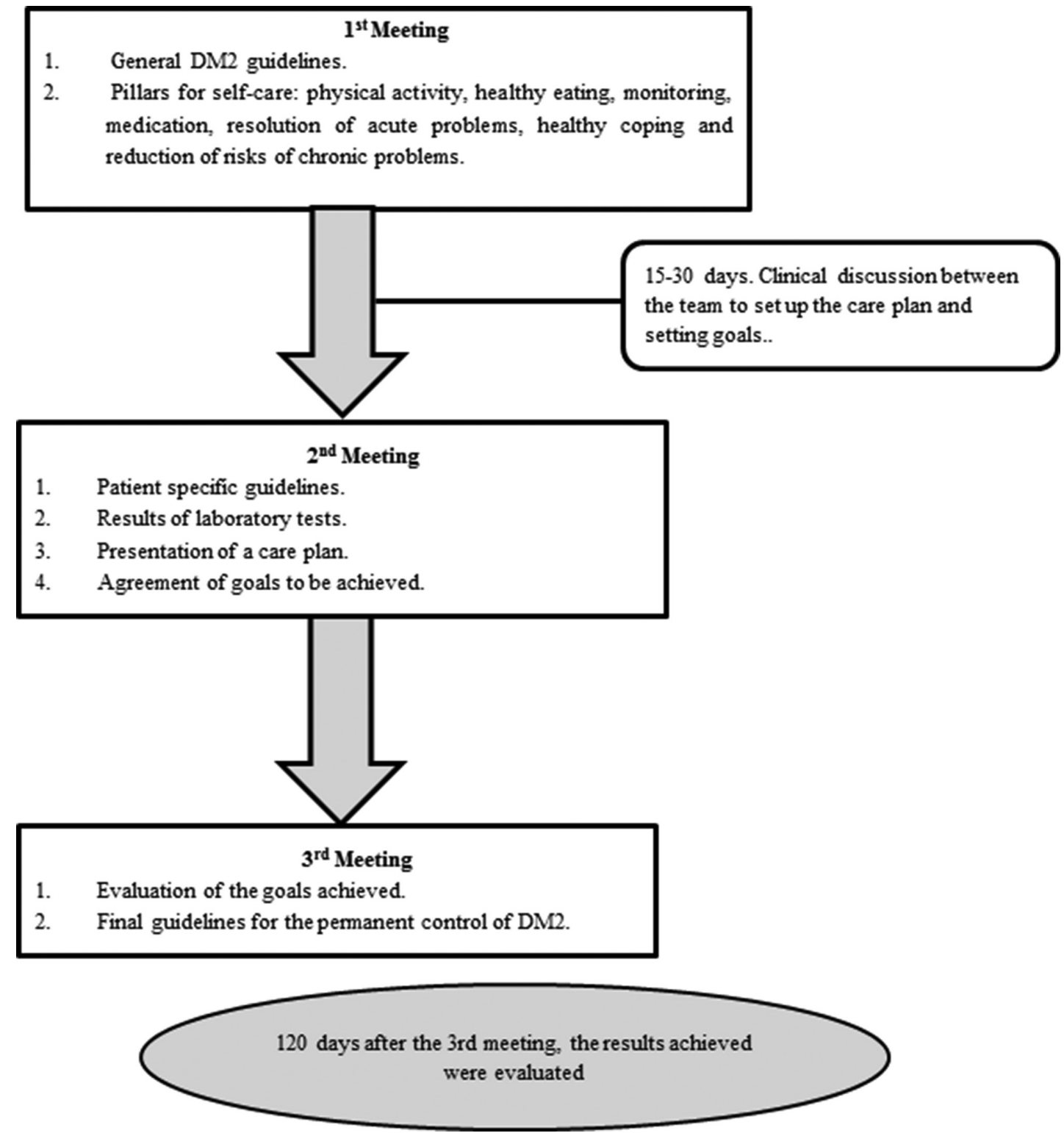

Figure 1 Characterization of the intervention: individual pharmacotherapeutic empowerment strategy. DM2, type 2 diabetes mellitus.

Higher values determine that the intervention is not cost-effective. $^{21}$

All analyses were performed considering a level of significance of $95 \%$. Data normality was evaluated using the Kolmogorov-Smirnov test. The comparison of the sociodemographic variables between intervention and control, and between the refusals and not found in the recruitment process groups was performed through the t-test and $\chi^{2}$ test. The analyses between the groups at baseline and follow-up were performed by the Student's t-test. The paired Student's t-test and McNemar test were conducted for intragroup comparison at baseline and follow-up. The analysis of covariance test was used to evaluate statistical difference $(p>0.05)$ between the intervention and control groups at follow-up, correcting the results by baseline data. The Statistical Package for Social Sciences (SPSS) V.19.0 software was used for all tests. Cost-effectiveness analyses and sensitivity analysis were performed with Excel 2010 software. The monetary amounts were obtained in Brazilian reais and converted into US $\$$ based on the quotation on 28 July 2012, through the website http://www4.bcb.gov.br/pec/conversao/ conversao.asp

\section{RESULTS}

A total of 352 patients were registered in the Hiperdia system of the FHS. Of these, $176(50 \%)$ were not eligible because they had a high cardiovascular risk $(n=165)$ or another type of diabetes $(n=11)$. A total of 176 patients were potentially eligible. Taking into consideration the exclusion criteria, 107 patients fulfilled all the requirements for participation in the study. The composition of the groups and the losses are presented in figure 1. 
Medications: Annual consumption of medication for each patient multiplied by the amount paid by the municipality in the bidding process for the year 2015 .

Medical consultations in basic care, nursing consultations and IPES: it was established that all professionals have a fixed consultation time of 30 minutes and the cost was calculated based on the value of the working hour of the year 2015. The cost of IPES was computed only for the intervention group.

Consultations with specialists, urgent and emergency healthcare: Table SIGTAP base/year 2015 that establishes the amounts paid by the SUS for certain procedures. Available at http://sigtap.datasus.gov.br/tabela-unificada/app/sec/inicio.jsp

\section{Hospitalization: total value of $\mathrm{AIH}$}

Figure 2 Methods of establishing costs. AIH, Authorization for Hospital Admission; IPES, individual pharmacotherapeutic empowerment strategy; SIGTAP, System of Management of the Table of Procedures, Medications and Orthotics, Prosthetics and Materials of the PHS; SUS=PHS, Public Health System.

The study population consisted mainly of women, with a mean age of $54.2( \pm 0.69)$ years in the intervention group and $53.9(+0.74)$ years in the control group, with $70 \%$ of the patients being less than 60 years in both groups. Most of the participants did not complete the fundamental level of schooling $(69.7 \%$ in the intervention group, $63.3 \%$ in the control group). In the intervention group, most of the individuals declared to be mixed race while in the control group they declared themselves white. Table 2 shows the sociodemographic characteristics of both groups, where no statistically significant difference was observed between the groups evaluated in this study $(\mathrm{p}>0.05)$.

Among the individuals belonging to the control group, the profile difference was analyzed in relation to the sociodemographic variables between the participants who refused and the participants who were not found during the recruitment process. There were no statistically significant differences between the intervention and control groups.

In the comparison between the groups, the variable 'other medications prescribed' showed a statistical difference in both baseline $(\mathrm{p}=0.032)$ and follow-up $(\mathrm{p}=0.01)$. It was possible to observe that the average number of medications used in the treatment of diseases other than DM2 was higher among patients in the control group when compared with the intervention group.

In the intragroup comparison, it was observed that only the urgent and emergency care variable presented statistical difference $(p<0.024)$, a result that suggests that IPES is able to significantly reduce the number and cost of care in the urgent and emergency variable (table 2). In the reference period of the research there was no eligible hospitalization in any of the groups, so this variable did not participate in the composition of the total cost.

It is observed that there was a reduction in the number of consultations in both groups when comparing baseline and follow-up. The variables of nursing consultation and consultation in specialized care had an average of less than one appointment/year. There was no hospitalization for DM2 or for its complications during the period evaluated.

The mean of medications prescribed for DM2 treatment was 1.1 in both groups. It should be emphasized that this study considered only medications obtained from municipal public pharmacies, excluding medication purchased with patients' own resources and by programs of the state and federal governments of Brazil. The mean of the total medications used by the patients was 4.1 in both periods of the study in the case of the intervention group, and 5.5 at baseline and 5.7 at follow-up for the control group.

Analyzing the total cost of the patient in the period of 1 year, values of US $\$ 113.40$ (baseline) and US $\$ 254.34$ (follow-up) were observed in the intervention group, and US $\$ 114.72$ (baseline) and US\$327.61 (follow-up) in the control group. However, this increase between the evaluated periods did not present statistical difference (p>0.05) (table 3).

For evaluation of the A1c outcome the patients were classified into controlled (A1c $\leq 7 \%$ ) and uncontrolled (A1c $>7 \%)$. At baseline of the intervention group there were $23(50 \%)$ controlled patients and $23(50 \%)$ uncontrolled patients, whereas in the control group there were $11(36.6 \%)$ controlled and $19(63.4 \%)$ uncontrolled. With the reduction in mean A1c of the intervention group from $7.359 \%$ to $7.0 \%$ at follow-up and of the control from $8.17 \%$ to $8.0 \%$ at follow-up, the number of controlled patients in the intervention group increased to $26(56.5 \%)$ and $13(43.3 \%)$ in the control group, however with no statistical difference ( $p>0.05)$.

In the cost-effectiveness calculation it is observed that in the group submitted to IPES, the reduction of 0.359 in A1c costs US $\$ 708.47$, while in the control group, the reduction of 0.170 in A1c costs US $\$ 1927.13$. These values 


\begin{tabular}{|c|c|c|c|}
\hline & & Intervention & Control \\
\hline \multicolumn{4}{|c|}{ Total annual follow-up cost } \\
\hline \multicolumn{2}{|c|}{ Minimum cost } & $A$ & D \\
\hline \multicolumn{2}{|c|}{ Mean cost } & $\mathrm{B}$ & E \\
\hline \multicolumn{2}{|c|}{ Maximum cost } & C & $\mathrm{F}$ \\
\hline \multicolumn{4}{|c|}{ Difference in A1c } \\
\hline \multicolumn{2}{|c|}{ Minimum effectiveness } & 1 & 4 \\
\hline \multicolumn{2}{|c|}{ Mean effectiveness } & 2 & 5 \\
\hline \multicolumn{2}{|c|}{ Maximum effectiveness } & 3 & 6 \\
\hline \multicolumn{4}{|c|}{ Scenarios } \\
\hline \multirow[t]{3}{*}{ A1 } & D4 & E4 & F4 \\
\hline & D5 & E5 & F5 \\
\hline & D6 & E6 & F6 \\
\hline \multirow[t]{3}{*}{ A2 } & D4 & E4 & $\mathrm{F} 4$ \\
\hline & D5 & E5 & F5 \\
\hline & D6 & E6 & F6 \\
\hline \multirow[t]{3}{*}{ A3 } & D4 & E4 & $\mathrm{F} 4$ \\
\hline & D5 & E5 & F5 \\
\hline & D6 & E6 & F6 \\
\hline \multirow[t]{3}{*}{ B1 } & D4 & E4 & F4 \\
\hline & D5 & E5 & F5 \\
\hline & D6 & E6 & F6 \\
\hline \multirow[t]{3}{*}{ B2 } & D4 & E4 & $\mathrm{F} 4$ \\
\hline & D5 & E5 & F5 \\
\hline & D6 & E6 & F6 \\
\hline \multirow[t]{3}{*}{ B3 } & D4 & E4 & F4 \\
\hline & D5 & E5 & F5 \\
\hline & D6 & E6 & F6 \\
\hline \multirow[t]{3}{*}{ C1 } & D4 & E4 & $\mathrm{F} 4$ \\
\hline & D5 & E5 & F5 \\
\hline & D6 & E6 & F6 \\
\hline \multirow[t]{3}{*}{ C2 } & D4 & E4 & $\mathrm{F} 4$ \\
\hline & D5 & E5 & F5 \\
\hline & D6 & E6 & F6 \\
\hline \multirow[t]{3}{*}{ C3 } & D4 & E4 & $\mathrm{F} 4$ \\
\hline & D5 & E5 & F5 \\
\hline & D6 & E6 & F6 \\
\hline
\end{tabular}

A1c, glycated hemoglobin.

show an ICER of $-\$$ R387.66, that is, the intervention is able to save US\$387.66 per patient/year for the health service. In the sensitivity analysis, after the construction of all scenarios, it was observed that the IPES was dominated in $19.8 \%$ (16 scenarios) of the simulated scenarios. In $80.2 \%$ of the remaining scenarios the IPES was cost-effective, being dominant in $30.9 \%$ of these scenarios, that is, in 25 of the 81 possible scenarios the intervention is able to reduce A1c at a lower cost when compared with traditional care, and in 40 trade-off scenarios it presents a lower cost-effective ICER, with values lower than US\$29 898.63 (table 4).

\section{DISCUSSION}

The constant technological innovations in health contribute to the increase in healthcare costs, which makes the development of pharmacoeconomic studies a necessity for health services. ${ }^{22}$ In public health services, it is known that the change in current care models is an alternative to try to balance the costs of DM2 treatment. ${ }^{23}$ In this sense, pharmacoeconomic analyses, such as those in this study, play an important role in the generation of data for the economic evaluation of pharmacotherapeutic empowerment strategies. The results demonstrate that the IPES insertion was able to promote glycemic control for the patient at a lower cost than the traditional care provided to the patient alone by the municipality, generating savings in resources and also considering the costs of their implementation.

The scarcity of pharmacoeconomic studies that evaluate the use of empowerment strategies makes it difficult to establish comparative parallels. In two Brazilian studies, cost-effectiveness analyses were performed considering pharmaceutical care services. Each controlled patient (A1c $<7 \%$ ) was able to generate an annual saving of US $\$ 163.54$ (US $\$ 2.35$ in 2015).$^{24}$ Obreli-Neto et al (2015) observed savings of US $\$ 660.80$ for each $0.7 \%$ reduction in Alc. ${ }^{25}$

As for the sensitivity analysis, the insertion of the intervention in the primary healthcare scenario of the municipality was dominant in relation to the traditional care offered. Similar methodology was adopted by Fonseca $e t$ al to evaluate the insertion of the human papillomavirus vaccine in the prevention of cervical cancer. ${ }^{26}$ In both cases, preventive interventions are dominant in relation to traditional care.

In other national studies with patients with DM, costs ranged from US\$281.80 patients/year (intervention group) and US $\$ 212.20$ patients/year (control group) to US $\$ 2108.00,{ }^{825}$ which may be related to the variables considered for cost composition (eg, different levels of comobility),${ }^{8}$ and also to the profile of the patients evaluated (elderly with different cardiovascular risks) ${ }^{25}$

Analyzing the number of medical consultations to which the patients had access within a year, it is observed that this average is close to that recommended by the Ministry of Health ${ }^{27} 28$ and similar to that found in another Brazilian study. ${ }^{25}$ These facts may suggest that the lack of glycemic control presented by the patients at the beginning of the study is not associated with the difficulty of accessing medical care, but rather with the lack of more effective strategies for their promotion.

When considering the number of nursing consultations, it is observed that the present study presents a number inferior to that found by Obreli-Neto et al (2015), ${ }^{25}$ who found an average of four annual 
Table 2 Sociodemographic characteristics of the intervention and control groups. Divinópolis, MG, 2017

\begin{tabular}{|c|c|c|c|c|}
\hline & & $\begin{array}{l}\text { Intervention, } \mathrm{n}(\%) \\
\mathrm{n}=46\end{array}$ & $\begin{array}{l}\text { Control, n (\%) } \\
n=30\end{array}$ & $P$ value \\
\hline Age & Mean & 54.2 & 53.9 & $0.904^{*}$ \\
\hline \multirow[t]{2}{*}{ Gender } & Female & $36(78.3)$ & 19 (63.3) & $0.155^{\star \star}$ \\
\hline & Male & $10(21.7)$ & $11(36.7)$ & \\
\hline \multirow[t]{4}{*}{ FHS } & Belvedere I e II & $13(28.3)$ & $7(23.3)$ & $0.846^{\star *}$ \\
\hline & Morada Nova & $9(19.6)$ & $8(26.7)$ & \\
\hline & Vale do Sol & $17(30.4)$ & $8(26.7)$ & \\
\hline & Nilda Barros & $10(21.7)$ & $7(23.3)$ & \\
\hline \multirow[t]{3}{*}{ Schooling (years) } & $<8$ & $32(69.7)$ & 19 (63.3) & $0.492^{* *}$ \\
\hline & $8-11$ & $8(17.4)$ & $4(13.4)$ & \\
\hline & $>12$ & $6(12.9)$ & $7(23.3)$ & \\
\hline \multirow[t]{3}{*}{ Race } & White & 17 (38.6) & $14(46.6)$ & $0.559^{\star \star}$ \\
\hline & Oriental/mixed & $22(50.0)$ & $12(40)$ & \\
\hline & Black/not declared & $5(11.4)$ & $4(13.4)$ & \\
\hline \multirow[t]{3}{*}{ Marital status } & Married & $34(73.9)$ & $18(59.9)$ & $0.201^{\star *}$ \\
\hline & Single or divorced & $7(15.2)$ & $4(13.4)$ & \\
\hline & Widowed or not declared & $5(10.9)$ & $8(26.7)$ & \\
\hline
\end{tabular}

${ }^{*}$ T Test; ${ }^{* *}$ Pearson's Chi-Squared Test

FHS, Family Health Strategy.

consultations. The nurse is an important professional in the process of empowering the patient, ${ }^{29}$ which may raise the suspicion that nursing care is responsible for the reduction of A1c. However, although the average number of nursing consultations was higher than the present study, Obreli-Neto et al (2015) achieved reduction of A1c in patients who participated in the study, emphasizing the importance of pharmaceutical assistance in the promotion of glycemic control.

Bahia et al found a variation of costs related to DM medication similar to this study (from US\$65.88 to US\$563.51). ${ }^{8}$ Regarding intragroup variation, the increase in costs in the follow-up period may be related to changes in the dosing regimen and to the insulinization of the patients, which consequently increases the consumption of inputs, contributing to higher costs. Medication can consume up to $50 \%$ of the direct costs related to $\mathrm{DM},{ }^{80}$ thus making the collection of these data relevant.

This study pointed to a significant reduction in the number of urgent and emergency services, a fact also observed in the study by Borges et al, ${ }^{31}$ which may show that pharmaceutical care services and pharmacotherapeutic empowerment strategies are able to reduce clinical situations that may lead to this type of care.

In a meta-analysis performed by Baldoni et al (2017), ${ }^{32}$ $66 \%$ of the studies that used strategies for the collective empowerment of patients with DM achieved the goal of reducing A1c. Norris et al (2001) achieved an average reduction of $0.26 \%$ A1c 4 months after the end of empowerment. ${ }^{33}$ Following a 1-year follow-up, Kræmer et al (2011) obtained an average reduction of $0.5 \%$ in the value of A1c. ${ }^{12}$

In this study, the mean reduction in A1c was $0.359 \%$ (intervention) and $0.17 \%$ (control). In the IPES the reduction of Alc was superior and $56 \%$ of the patients managed to obtain glycemic control (A1c <7\%). Although the data do not present statistical difference, glycemic control is related to the improvement of quality of life, reduction of complications, and reduction of costs related to $\mathrm{DM},{ }^{23} 34$ therefore, these strategies should always be preferable from the management of the services point of view.

Analyzing the number of drugs prescribed for the treatment of DM2, in the study by Borges et al (2011) ${ }^{31}$ the mean approaches two drugs per patient. The difference between the two studies may be related to the methodology adopted. While Borges considered any medication prescribed for DM, the present study considered only those obtained in municipal public pharmacies. This study considered only drugs obtained in municipal public pharmacies, excluding drugs purchased with patients' own resources and by programs of the state and federal governments of Brazil, which may be cited as a limitation of the study. It is known that many patients access the drug metformin $500 \mathrm{mg}$ XR (recommended as monotherapy for the treatment of $\mathrm{DM} 2^{1}$ ) through the 'Popular Pharmacy' program, however, all the work was performed from the perspective of the municipal system and therefore the absence of data from this program should not compromise these findings. 


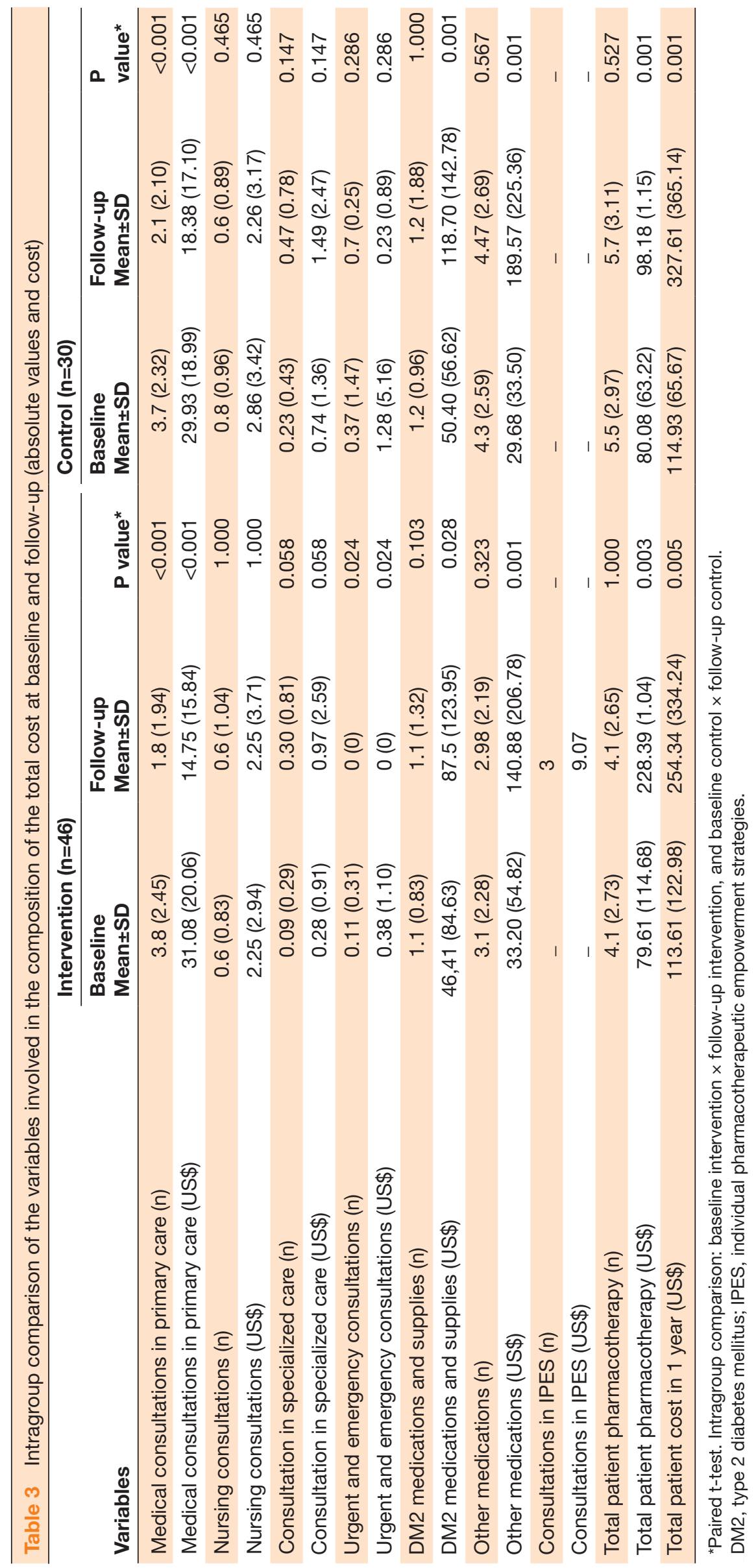


Table 4 Cost-effectiveness analysis and sensibility analysis of the individual pharmacotherapeutic empowerment strategy

\begin{tabular}{|c|c|c|}
\hline & $\begin{array}{l}\text { Intervention } \\
\text { (conventional treatment+IPES) }\end{array}$ & $\begin{array}{l}\text { Control } \\
\text { (conventional treatment) }\end{array}$ \\
\hline \multicolumn{3}{|l|}{ Cost and outcome analyses } \\
\hline Costs (total patient cost in 1 year (US\$)) & 254.34 & 327.61 \\
\hline Outcome (reduction in A1c) & 0.359 & 0.170 \\
\hline $\begin{array}{l}\text { Cost-effectiveness ratio (US\$/reduction in } \\
\text { A1c) }\end{array}$ & 708.47 & 1927.13 \\
\hline Incremental cost-effectiveness ratio & & $(254.34-327.61) /(0.359-0.170)=387.67$ \\
\hline \multicolumn{3}{|l|}{ Sensitivity analysis } \\
\hline \multicolumn{2}{|c|}{ Dominated (highest cost $\times$ lowest effectiveness) } & 16 scenarios $-19.2 \%$ \\
\hline \multicolumn{2}{|c|}{ Trade-off (ICER > GDP per capita) - IPES very cost-effective } & 40 scenarios $-50.1 \%$ \\
\hline \multicolumn{2}{|c|}{ Dominant (lowest cost $\times$ highest effectiveness) } & 25 scenarios $-30.9 \%$ \\
\hline
\end{tabular}

A1c, glycated hemoglobin; GDP, gross domestic product; ICER, incremental cost-effectiveness ratio; IPES, individual pharmacotherapeutic empowerment strategy.

Despite the limitations described in this study, such as the absence of randomization of the sample and the composition of costs only from the municipal point of view, its innovative characteristic can be highlighted in relation to the pharmacological analysis of the pharmacotherapeutic empowerment strategies and the presence of a control group to extrapolate the results obtained. These studies become important tools in the promotion of the economic evaluation in health from the perspective of municipal management, and can aid in the decision-making process.

\section{CONCLUSION}

Pharmacoeconomic analyses are still innovative when the strategies of empowerment for patients with DM2 are in question. The generation of results that can be used to guide possible decision-making as well as to subsidize new research can be considered a breakthrough in the view of municipal public health.

The IPES is a viable alternative, both clinically and economically, to the reality of the health system of the municipality analyzed. The patients served by the IPES had traditional care maintained, and the IPES presented a more cost-effective result, which was reinforced by the sensitivity analysis. The present study provides support for management orientation in the decision process, supporting the insertion of the pharmacist in primary healthcare teams, providing the population with recommended multiprofessional healthcare.

Acknowledgements We thank the Coordination of Improvement of Higher Level Personnel-CAPES for the support to the Graduate Program of Pharmaceutical Science of the CCO campus, Federal University of São João del-Rei.

Contributors ACOG, MSC, CS, AMTC and AOB contributed to the design, collection, analysis and interpretation of data. LRLP and JAA participated in the critical review of the work content. All authors participated in the final approval of the version to be published.

Funding The authors have not declared a specific grant for this research from any funding agency in the public, commercial or not-for-profit sectors.
Competing interests None declared.

Patient consent for publication Not required.

Ethics approval The study was approved by the Research Ethics Committee of the Federal University of São João Del-Rei, Dona Lindu Central-West (Centro-Oeste) Campus (UFSJ-CCO), No CAAE 32787914.0.0000.5545, and is registered in the Brazilian Registry of Clinical Trials (ReBEC) under No RBR-6t4qmn.

Provenance and peer review Not commissioned; internally peer reviewed.

Data availability statement All data relevant to the study are included in the article or uploaded as supplementary information.

Open access This is an open access article distributed in accordance with the Creative Commons Attribution Non Commercial (CC BY-NC 4.0) license, which permits others to distribute, remix, adapt, build upon this work non-commercially, and license their derivative works on different terms, provided the original work is properly cited, appropriate credit is given, any changes made indicated, and the use is non-commercial. See: http://creativecommons.org/licenses/by-nc/4.0/.

\section{REFERENCES}

1. Sociedade Brasileira de Diabetes (SBD). Diretrizes da Sociedade Brasileira de Diabetes: 2014-2015. São Paulo: AC Farmacêutica, 2015.

2. Organização Mundial da Saúde (OMS). Definition and diagnosis of diabetes mellitus and intermediate hyperglycemia, 2006.

3. American Diabetes Association (ADA). Standards of Medical Care in Diabetes. Diabetes Care 2016;39(Suppl 1).

4. Silva IJ, Cardoso P-RH, et.al. Efeitos do Apoio Social na Qualidade de Vida, Controlo Metabólico e Desenvolvimento de Complicações Crónicas em Indivíduos com Diabetes. Psicologia, Saúde \& Doenças 2003:4:21-3.

5. Pereira DS, Nogueira JAD, Silva CAB. Qualidade de vida e situação de saúde de idosos: um estudo de base populacional no Sertão Central do Ceará. Rev Bras Geriatr Gerontol 2015;18:893-908.

6. Gross JL, Nehme M. Detecção e tratamento das complicações crônicas do diabetes melito: Consenso da Sociedade Brasileira de Diabetes e Conselho Brasileiro de Oftalmologia. Rev Assoc Med Bras 2000;3:279-84.

7. Henriksson F, Agardh CD, Berne C, et al. Direct medical costs for patients with type 2 diabetes in Sweden. $J$ Intern Med 2000:248:387-96.

8. Bahia LR, Araujo DV, Schaan BD, et al. The costs of type 2 diabetes mellitus outpatient care in the Brazilian public health system. Value Health 2011:14(5 Suppl 1):S137-S140.

9. Guidoni CM, Olivera CMX, Freitas Ode, et al. Assistência ao diabetes no Sistema Único de Saúde: análise do modelo atual. Brazilian Journal of Pharmaceutical Sciences 2009;45:37-48.

10. Kleba ME, Wendausen A. Empoderamento: processo de fortalecimento dos sujeitos nos espaços de participação social e democratização política. Saúde soc 2009;4:733-43. 
11. Tol A, Baghbanian A, Mohebbi B, et al. Empowerment assessment and influential factors among patients with type 2 diabetes. $J$ Diabetes Metab Disord 2013;12.

12. Kraemer DF, Kradjan WA, Bianco TM, et al. A randomized study to assess the impact of pharmacist counseling of employer-based health plan beneficiaries with diabetes: the EMPOWER study. $J$ Pharm Pract 2012;25:169-79.

13. Hermanns N, Kulzer B, Ehrmann D, et al. The effect of a diabetes education programme (PRIMAS) for people with type 1 diabetes: Results of a randomized trial. Diabetes Res Clin Pract 2013;102:149-57.

14. Aquino JA, Baldoni AO, Di Lorenzo Oliveira C, Oliveira CDL, JÁ A et al. Pharmacotherapeutic empowerment and its effectiveness in glycemic control in patients with diabetes mellitus. Diabetes Metab Syndr 2019;13:137-42.

15. Dawber TR. The Framingham study. The epidemiologic of atherosclerotic disease. Cambridge: Harvard University Press, 1980

16. Naik AD, Palmer N, Petersen NJ, et al. Comparative effectiveness of goal setting in diabetes mellitus group clinics: randomized clinical trial. Arch Intern Med 2011;171:453-9.

17. Aquino JA, Baldoni AO, Oliveira CL, et al. Educational booklet on diabetes: construction and content validation. Semina: Ciências Biológicas eLondrina: da Saúde, 2016: 37. 77-82.

18. Rascati KL. Introdução Farmacoeconomia. 1 ed. Artmed: Porto Alegre, 2010.

19. Brennan A, Bansback N, Reynolds A, et al. Modelling the costeffectiveness of etanercept in adults with rheumatoid arthritis in the UK. Rheumatology 2004;43:62-72.

20. Instituto Brasileiro de Geografia e Estatística. Contas Nacionais. PIB per capta. Available: http://brasilemsintese.ibge.gov.br/contasnacionais/pib-per-capita.html [Accessed 2 june 2017].

21. Saúde BMda, Ciência Sde. Tecnologia e Insumos Estratégigos. Departamento de ciencia e Tecnologia. Brasília: Diretrizes metodológicas: Diretriz de avaliação econômica, 2014.

22. Ademi Z, Kim H, Zomer E, et al. Overview of pharmacoeconomic modelling methods. Br J Clin Pharmacol 2013;75:944-50.

23. Arredondo A, Icaza E. Costos de la Diabetes en America Latina: Evidencias del Caso Mexicano. International Society for Pharmacoeconomics and Outcomes Research (ISPOR). . Published by Elsevier Inc. Value In Health. n, 2011: 14. 85-8.

24. Picoli RM. Análise de custo efetividadeda atenção farmacêutica no tratamento do diabetes mellitus tipo 2. Universidade de São Paulo - Campus Ribeirão Preto, 2015. Available: http://www.teses. usp.br/teses/disponiveis/96/96132/tde-02092015-100832/pt-br.php [Accessed 30 March 2017].

25. Obreli-Neto PR, Guidoni CM, de Oliveira Baldoni A, et al. Effect of a 36-month pharmaceutical care program on pharmacotherapy adherence in elderly diabetic and hypertensive patients. Int $J$ Clin Pharm 2011;33:642-9.

26. Fonseca AJ, Ferreira LCL, Balbinotto GN. Custo-efetividade da vacina contra a humana papilomavírus na Amazônia brasileira. Rev Assoc Bras Med 2013;59:442-51.

27. Brasil. Ministério da Saúde. Secretaria de Atenção Saúde. Departamento deAtenção Básica. Estratégias para o cuidado da pessoa com doença crônica:diabetes mellitus. Brasília: Cadernos de Atenção Básica, 2013a: 36.

28. Saúde BMda. Secretaria de Atenção Saúde. Departamento de Atenção Básica. Estratégias para o cuidado da pessoa com doença crônica: diabetes mellitus. Brasília: Cadernos de Atenção Básica, 2013b: 36.

29. Hammerschimidt KSA, Lenardt MH. Tecnologia educacional inovadora para $\mathrm{O}$ empoderamento junto a idosos com diabetes mellitus. Brasil: Texto, Contexto, Enferm, 2010: 19. 358-65.

30. Marinho MGdaS, Cesse EduardangelaPessoa, Bezerra AFB, et al. Análise de custos da assistência saúde aos portadores de diabetes melito e hipertensão arterial em uma unidade de saúde pública de referência em Recife. Brasil Arq Bras Endocrinol Metab 2011;55:406-11.

31. Borges APdeS, Guidoni CM, Freitas Ode, et al. Economic evaluation of outpatients with type 2 diabetes mellitus assisted by a pharmaceutical care service. Arq Bras Endocrinol Metab 2011;55:686-91.

32. Baldoni NR, Aquino JA, Sanches-Giraud C, et al. Collective empowerment strategies for patients with diabetes mellitus: a systematic review and meta-analysis. Prim Care Diabetes 2017:11:201-11.

33. Norris SL, Engelgau MM, Narayan KM. Effectiveness of selfmanagement training in type 2 diabetes: a systematic review of randomized controlled trials. Diabetes Care 2001;24:561-87.

34. Lachin JM, Orchard TJ, Nathan DM, et al. Update on cardiovascular outcomes at 30 years of the diabetes control and complications trial/epidemiology of diabetes interventions and complications study. Diabetes Care 2014;37:39-43. 